\title{
SEASONAL EFFECTIVENESS OF PUMP-AND-TREAT REMEDIATION IMPACTED BY WATER TABLE FLUCTUATION
}

\author{
Elias Teramoto ${ }^{1}$, Marco Pede ${ }^{1}$, and Hung Chang $^{1}$ \\ ${ }^{1}$ São Paulo State University
}

April 28, 2020

\begin{abstract}
The pump-and-treat methodology represents a common remediation approach to mitigate hydrocarbon contaminations. In a well-studied site contaminated by large volume of jet fuel, continuous monitoring of the water table and floating phase thickness at a widely studied site contaminated by a large volume of jet fuel revealed the phenomenological process governing the effectiveness of the site's active remediation system. The floating phase thickness recorded in the monitored wells broadly varied and was negatively correlated with the water table level. Although the dependency of LNAPL thickness on water table fluctuations is widely recognized, the LNAPL recovery, which is governed by alternating cycles of release and entrapment of LNAPL in pore spaces, has been poorly described. Thus, we present a peculiar case in which the LNAPL recovery is expected only episodically, when water table falls sufficiently. In the period spanning from 2006 to 2008, LNAPL remediation recovered nearly $180 \mathrm{~m} 3$ of oil. In later years, the volume of recovered LNAPL declined and ceased between 2010 and 2014 , when the water table rose. The conditions observed at the study site are likely common and may have important implications in the management of contaminated sites.
\end{abstract}

\section{INTRODUCTION}

Petroleum-derived fuels represent an important source of energy in contemporary society (Dudley, 2018). Accidental releases due to storage tank leaks, pipeline ruptures or improper waste disposal represent widespread groundwater contamination threats posed by petroleum hydrocarbons (e.g., gasoline, jet fuel and diesel). Whenever fuel is released in a large volume or the release persistently occurs over a long period, many hydrocarbons can migrate and reach the uppermost portion of a saturated zone; from there, these hydrocarbons accumulate and form a Light Non-Aqueous Phase Liquid (LNAPL) (ITRC, 2009; Tomlinson et al., 2017). Once present in a subsurface environment, the petroleum is distributed in a non-aqueous phase in pores within a multiphasic context and releases soluble and also volatile compounds into water by interphase mass-transfer, especially BTEX (benzene, toluene, ethylbenzene and xylenes). Since the BTEX compounds released to groundwater are soluble, mobile, and pose carcinogenic or neurotoxic risks to humans, providing accurate predictions of BTEX movement patterns and final deposition locations within a saturated zone is crucial to establish remediation goals and actions in petroleum-contaminated site management (e.g., MacDonald and Kavanaugh, 1994; Chesnaux, 2008).

Since the soluble or volatilized compounds of LNAPL pose risks to human health (e.g., Peters et al., 1999; Huntley and Beckett, 2002; Baciocchi et al., 2010; Thornton et al., 2013), management efforts should reduce contaminant masses within the sub-surface. Collective actions that facilitate the extraction or destruction of a contaminant are known as remediation. Active remediation, based on physical extraction, represents the most common strategy to clean subsurface leaks. Among active remediation techniques, the pump-and-treat 
(P\&T) method represents the simplest and traditional approach used to promote LNAPL recovery. The P\&T approach consists of a simple extraction of both LNAPL and contaminated groundwater from wells, followed by a treatment of contaminated water prior to disposal. P\&T normally is highly expensive and timeconsuming. Despite elevated efforts and investments devoted to site cleanup, physical remediation cannot fully extract hydrocarbons in the subsurface, as previously demonstrated by several works such as Mercer (1990), McCray et al. (2011), Lenhard et al. (2018), and Lari et al. (2018). After a remediation based solely on the P\&T approach, a large proportion of LNAPL will remain in the pores and the remediation goal will be not reached.

Geological heterogeneity has frequently acted as a main impediment to oil recovery within remediation systems (Kaluarachchi, 1996; Waddill \& Parker, 1997; McCray et al., 2011; Saenton \& Illangasekare, 2013). Low permeability lithologies impede the movement of non-aqueous fluids. According to Mercer (1990) and McCray et al. (2011), most contaminant removals occur in hydraulically accessible zones, and complete removals are limited by contaminant masses stored in inaccessible zones. However, regardless of the importance of geological heterogeneity, the main cause of complications to LNAPL remediations is the complexity of LNAPL distributions in pore spaces; these complications are accentuated by water table fluctuations.

The multiphase distributions of hydrocarbons, water and air in pore spaces represent a complex issue and affect the LNAPL remediation ability. Only a limited proportion of LNAPL is mobile and can be recovered, while a large proportion will remain immobile as a residual or entrapped phase. More complex scenarios have been observed in the field in response to water table fluctuations caused by alternating wet and dry seasons. When a water table falls to a position not previously recorded after the spill, LNAPL migrates to lower parts of the aquifer (Kemblowski \& Chiang, 1990; Charbeneau, 2007, Jeong \& Charbeneau, 2014). When the water level rises, LNAPL is retained through capillary force in the saturated zone; this phenomenon is known as entrapment (Kemblowski \& Chiang, 1990, Marinelli \& Durnford, 1996; Steffy et al., 1998; Charbeneau et al., 2007; Teramoto \& Chang, 2017). When entrapment occurs, LNAPL becomes entrained in the saturated zone by capillary forces, thereby losing its mobility. Conversely, when the water level drops and water is drained from the pores, the LNAPL is released and the previously isolated drops and ganglia agglutinate and gain mobility. According to Parcher et al. (1995), the LNAPL residual phase resulting from the vertical movement of the water level is small in the unsaturated zone, where the pores are occupied by air, LNAPL and water; conversely, the phase is high in the saturated zone, where water and LNAPL occupy completely the porous medium. According to Mercer \& Cohen (1990), the residual saturation of LNAPL ranges from 10 to $20 \%$ in the unsaturated zone. As demonstrated by Chaberneau \& Jeong (2014), Lenhard et al. (2017) and Lenhard et al. (2018), LNAPL in free, entrapped, and residual phases, as well as its relative permeability, are time-variant and depend of the elevation of the fluid phase level. The analytical model presented by Lenhard et al. (2018) and the experimental results of Gatsios et al. (2018) reinforce that entrapment induced by a water table fluctuation represents the most prominent challenge to active remediation effectiveness. As previously demonstrated by Wang et al. (2014), Jeong \& Chaberneau (2014) and Kuo et al. (2016), the recovery rate of LNAPL is intrinsically controlled by water table fluctuations.

Our study site, contaminated by a large volume of jet fuel in Brazil, has been characterized by several works, including Bordignon et al. (2016), Teramoto and Chang (2017), Teramoto and Chang (2018), Isler et al. (2018) and Teramoto and Chang (2019). As demonstrated by Teramoto \& Chang (2017) and Isler et al. (2018), most of the LNAPL is distributed in the entrapped phase below the water table, thereby impacting the effectiveness of pump-and-treat remediation. This study presents a phenomenological process related to the seasonal effect impacting the water table level that governs LNAPL recovery; this study's findings can provide support to new strategies of remediation, especially in tropical climates.

\section{WIDE-RANGING WATER TABLE FLUCTUATIONS IN BRAZIL}

The southeast Brazil encompass a subtropical to tropical climates, has a well-defined wet period during the summer (December-January-February) and a well-defined dry period during the austral winter (JuneAugust). During autumn (March-May) and spring (September-November), the region receives an intermediate precipitation volume that falls between the typical values observed in summer and winter. The water 
table fluctuation in shallow aquifers reflects hydrogeological and climatic conditions. Tropical regions, such as most of Brazil, are typically characterized by a high amount of precipitation, with alternating dry and wet seasons. Because of the large volume of precipitation in the wet season, the groundwater recharge is also higher at this time, leading to a wide range water table fluctuation.

Figure 1 illustrates the alternating rainy (October to March) and dry seasonal precipitation (April to September), previously presented by Teramoto and Chang (2017). The seasonal variation in precipitation generates a cyclic water-level fluctuation (Healy \& Cook, 2002; Maréchal et al., 2006; Delin et al., 2007; Neto et al., 2015) similar to those observed in Figure 1. A time lag of nearly three months occurs in the study area between the peak of the rainy season and the peak of the groundwater-level rise. The groundwater-level maximum is generally reached in May and falls steadily until December. The amplitude of the water level is directly related to the amount of annual accumulated rainfall (Teramoto and Chang, 2018).

Figure 2 illustrates six hydrograms in several locations of south and southeast Brazil, showing that water table fluctuations mostly displayed variation ranges above four meters over time.

\section{MATERIAL AND METHODS}

\section{Study site}

The study area is located in the municipality of Paulínia, São Paulo, Brazil. A large volume of jet fuel is present in the subsurface, with an estimated volume of $520 \mathrm{~m}^{3}$ (Pede, 2009). To determine the extents of LNAPL and the plumes from the dissolved phase of BTEX compounds, 104 monitoring wells were installed in an area of $264,600 \mathrm{~m}^{2}$. Figure 3 shows a potentiometric map with the inferred boundary of the source zone, monitoring locations, and pumping wells in the study area. The source zone occupied an area of approximately $80,000 \mathrm{~m}^{2}$.

The studied Cenozoic shallow aquifer is heterogeneously composed of clayey sands interfingered with coarse sand lenses, sandy clays and clayey silts. The geometries of the sandy and clayey facies indicate a depositional environment dominated by a meandering river (Bordignon et al., 2015; Teramoto et al., 2017b). The hydraulic conductivity $(\mathrm{K})$ displays a high variability because it is intrinsically related to aquifer lithology. $\mathrm{K}$ values determined by slug tests performed on 64 monitoring wells range from $1.2 \times 10^{-7} \mathrm{~m} / \mathrm{s}$ to $2.4 \times 10^{-4} \mathrm{~m} / \mathrm{s}$, with a geometric mean of $2.8 \times 10^{-5} \mathrm{~m} / \mathrm{s}$. The average hydraulic gradient is 0.0036 in the northeast region and increases toward the discharge zone in the southwest, reaching values of 0.0176 .

\section{Monitoring}

Since 2002, the water level and free phase thickness of the study site have been measured using an interface probe in the monitoring wells at a biweekly frequency. This recorded time-series information has made it possible to construct hydrographs and determine the floating phase thickness variation for each monitoring well.

\section{Remediation setup}

At the study site, 20 pumping wells (Figure 3 ) currently operate with a flow rate ranging from 0.087 to 15 $\mathrm{m}^{3} /$ day. The extracted fluids are removed into a separator box. When the contaminated water is directed to the treatment station, the oil is stored in individual containers. The storage of extracted LNAPL in individual tanks can be used to evaluate the performance of each pumping well, thereby allowing an evaluation of the spatial variability of aquifer parameters controlling the oil recovery.

\section{Theorical basis of LNAPL recovery}

A detailed description of an LNAPL distribution and its movement to a well is described in Chaberneau (2007). In this section, we will demonstrate the main formulations that moved the flowing LNAPL during pumping-and-treat remediation, following the analytical model presented by Chaberneau (2007).

The floating phase thickness $\left(b_{n}\right)$ recorded in monitoring wells represents the most common criteria used to predict LNAPL distributions based on the relationship of capillary pressure/saturation, as demonstrated 
by Kemblowski and Chiang, 1990, Marinelli and Durnford, 1996, Sleep et al. (2000) and Lenhard et al. (2018). Assuming an equilibrium condition between fluids within the well and the surrounding formation, the floating phase thickness can be used to assess corresponding energy conditions within the pores of the formation (Figure 4).

The residual saturation of the nonwetting phase shown in Figure 4 is a measurement of the porous medium capacity used to retain nonwetting fluid during re-filling with the water. The LNAPL head to water head plus the equilibrium of LNAPL-layer thickness in a well is described by Eq. 1.

$h_{n}=z_{\mathrm{an}}=h_{w}+\left(1-\rho_{r}\right) b_{n}(1)$

Where $\rho_{r}$ represents the density ratio of the LNAPL over water (pw).

The LNAPL saturation $\left(S_{n}\right)$ in the given vertical interval of the smear zone (i.e. $z>z_{\text {an }}$ ) may be defined by Eq. 2 .

$S_{n}(z)=S_{\mathrm{nr}}+\left(1-S_{\mathrm{wr}}-S_{\mathrm{nr}}\right)\left(S_{e[t]}-S_{e[w]}\right)(2)$

Where $S_{\mathrm{wr}}, S_{\mathrm{nr}}, S_{e[w]}, S_{e[t]}$, respectively represent the water residual saturation, LNAPL residual saturation, and total liquid effective saturation.

A significant portion of saturation was not mobile and was retained by capillary forces in the pore space. Several laboratories have derived experiments, such as Johnston and Adamski (2005), showing that the residual LNAPL saturation values, $S_{n r}$, linearly increase with the initial LNAPL saturation values of (1 $\left.-S_{w i}\right)=S_{n i}$.

The LNAPL obstructs part of the pore space and reduces the permeability, creating a profile of intrinsic permeability related to $S_{n}$ (Figure 4). The relative permeability in a multiphase context may be calculated using the Mualem equation (Eq. 3).

$k_{\mathrm{rn}}\left(S_{w}, S_{n}\right)=\sqrt{S_{e[t]}-S_{e[w]}}\left(\frac{\int_{S_{e[t]}}^{S_{e[t]}} \frac{d S_{e}}{h_{c}}}{\int_{0}^{1} \frac{d S_{e}}{h_{c}}}\right)^{2}(3)$

The extraction of contaminated groundwater through pumping wells creates a gradient that causes LNAPL migration towards the well. Larger groundwater pumping rates correspond to larger hydraulic gradients toward the well and an increased LNAPL flow.

The water transmissivity in a screened interval lacking LNAPL is defined by Eq. 4, while the LNAPL transmissivity is calculated by integrating the relative permeability within the smear zone, as defined by Eq. 5 .

$T_{w}\left(b_{w}\right)=\int_{z_{\mathrm{an}}-b_{w}}^{z_{\mathrm{aw}}} K_{\mathrm{ws}}(z) \mathrm{dz}(4)$

$T_{n}\left(b_{n}\right)=\frac{\rho_{r}}{\mu_{r}} \int_{z_{\mathrm{nw}}}^{z_{\max }} K_{\mathrm{ws}}(z) k_{\mathrm{rn}}\left(S_{w}, S_{n}\right) d z(5)$

The multiphase extraction by pumping recovered groundwater at rates of $Q_{w}$, over a screened interval of $b_{w}$. The flow of water to the pumping wells also impacted the flow of LNAPL at rate $Q_{n}$. The flow rate of LNAPL recovered by the pumping well can be estimated via the transmissivity of LNAPL (Eq. 4) and the water transmissivity (Eq. 5), according to Eq. 6.

$Q_{n}=\frac{Q_{w} T_{n}\left(b_{n}\right)}{T_{w}\left(b_{w}\right) \rho_{r}}(6)$

The LNAPL's specific volume $\left(D_{n}\right)$ serves as reference to quantify the amount of LNAPL present as a function of the floating phase measured in the monitoring wells. $D_{n}$ corresponds to the area under the LNAPL saturation curve (Figure 4), and it is calculated by an integration of $\mathrm{S}_{\mathrm{n}}$ within the smear zone, assuming a porosity $\varnothing$.

$D_{n}\left(b_{n}\right)=\int_{z_{\mathrm{nw}}}^{z_{\max }} \varnothing S_{n}(z) \mathrm{dz}(7)$ 
Only a fraction of $D_{n}$ showed mobility and was subject to recovery. The LNAPL recoverable volume, $R n$, is determined by the area between the LNAPL saturation curve and the residual saturation curve.

$R_{n}\left(b_{n}\right)=\int_{z_{\mathrm{nw}}}^{z_{\max }} \varnothing\left(S_{n}(z)-\left(S_{\mathrm{nr}}(z)\right) d z(8)\right.$

All equations presented later in this study are based on the premise of equilibrium and static conditions, in which the LNAPL is completely released from the pore space and all revocable LNAPL can be recovered by the pumping wells. However, in the field, due to the upward movement of the water table, the pore space of the smear zone is imbibed with water and the LNAPL is entrapped by capillary forces, resulting in a decrease of the floating phase in monitoring wells. When the water table is below the top of the smear zone (Figure $5 a)$, the LNAPL flows to the pumping well due to the hydraulic gradient created by water extraction. When the water table rises above the top of the smear zone, the LNAPL is fully entrapped and the floating phase disappears from the monitoring wells; thus, no LNAPL can be recovered from the pumping wells (Figure 5b). Moreover, most analytical models (e.g., Chaberneau and Jeong, 2014; Lenhard et al., 2017; Alfaro et al., 2019) have not incorporated the hysteresis effect imposed by recurrent cycles of drainage and imbibition of the pores with respect to the wetting phase imposed by water table fluctuations.

To estimate the volume of recoverable LNAPL in favorable conditions, when the water table fell and released the LNAPL from the pore space, we performed simulations using the measured floating phase thickness, physical aquifer parameters, and characteristics of LNAPL with an assumption of vertical equilibrium. Using the analytical model of Jeong and Chaberneau (2014), we simulated fifteen years of LNAPL recovery assuming ideal conditions, in which the water table remains static and the LNAPL can be recovered by the imposition of a hydraulic gradient induced by pumping.

Physical parameters of aquifers

Because the physical properties of porous media play an important role in mass transfers, an aquifer characterization was executed using lithological data, hydraulic conductivity data, and retention curve parameters extracted from previous studies (Bordignon et al., 2015; Teramoto and Chang, 2018).

Due to the difficulty in accessing undisturbed aquifer samples in the sub-surface, we collected similar samples in the outcrop close to the study site. We performed measurements of the water matric potential in the laboratory as a function of sample moisture to build a retention curve using Richards' plate apparatus and the filter paper test. The generated points were fitted by the van Genuchten model (van Genutchen, 1981).

\section{LNAPL characterization}

Characterization of LNAPL were performed in six floating phase samples collected from the monitoring wells. The kinematic viscosity values were obtained by methodology described in ASTM D445 standard, with the unit of viscosity expressed in Stokes (St). To determine the surface and interfacial tension of the fluids present in the porous medium, samples of water and oil were collected along the free phase plume. Four water samples and four oil samples were collected to measure the interfacial and surface tension of both fluids.

The quantification of surface tension and interfacial tension between the liquids was performed according to the ring method (Du Nouy), using a Sigma $701 \mathrm{KSV}$ tensiometer according to the procedures of ASTM D 971-99a. The test consists of determining the surface and interfacial tension by measuring the force required to detach a platinum ring (of known characteristics) by passing it through the air-water interface, and then air-LNAPL and water-LNAPL, respectively. The tests were performed at a constant temperature of $25 \pm 1$ ${ }^{\circ} \mathrm{C}$ with two conditions for descent speed and plate climbing (20 and $25 \mathrm{~mm} . \mathrm{min}^{-1}$, respectively), to verify if the difference in speeds significantly interfered with the measurement.

\section{RESULTS}

\section{Water table fluctuation and floating phase thickness}

The water table fluctuation of the fall and rise of the water table observed in Figure 2, may be interpreted as 
recurrent cycles of drainage and imbibition of smear zone pores. During the upward movement of the water table during groundwater recharge, understood as an imbibition cycle, the wetting phase enters the pores and entraps the non-aqueous phase. Because the entrapment condition, the LNAPL lose its mobility, leading to decrease or even disappearance of the floating phase into the monitoring wells. In opposite condition, the downward movement of groundwater during dry seasons may be interpreted as a drainage event, since the water filling the pores is drained and the non-aqueous phase is released, gaining mobility. The freed LNAPL can migrate to monitoring wells and the thickness of floating phase into the monitoring wells increases. The alternating cycles of entrapment and release of LNAPL is easily identified in the combined time-series of water table height and floating phase thickness. Figure 6 illustrates the water table fluctuation and floating phase thickness variation during the period spanning April 2006 and January 2015 in four monitoring wells. Invariably, the recorded floating phase thickness is generally smaller during periods of elevated water levels and progressively increases when the water table falls.

The cycles of entrapment and release of LNAPL is best characterized by maps of floating phase thickness (Figure 7). Figure 7 presents the floating phase thickness isovalues in different periods of monitoring study, showing large variation over time. The maximum floating phase thickness was observed in the interval of May to November 2008 (Figure 7a), while the minimum floating phase thickness was recorded in May 2012.

\section{Recorded LNAPL recovery}

The study area has been investigated since 2002, with a pump-and-treat remediation system in place since 2005. Initially, the remediation system operated with four pumping wells (PB-01, PB-02, PB-03 and PB-04. From 2006 to 2009, four additional wells were incorporated into the system (PB-05, PB-06, PB-07, PB-08). From December 2010 to April 2011, the remediation was paused and on April 2011, the operation resumed with 20 active pumping wells.

The LNAPL recovery rate of the remediation system broadly varied over time. At beginning of remediation until November 2005, a neglectable volume of oil was recovered. The period between October 2005 and March 2006 saw a recovery of $4.25 \mathrm{~m}^{3}$ of LNAPL. By March 2006, the LNAPL recovery rate strongly decreased. In November 2006, there was an abrupt increase of LNAPL recovery in pumping wells PB-03, PB-05, PB-06 and PB-07 (Figure 8), which correlated with a strong decrease in the water table observed during this period. Between October 2006 and March 2007, $84.67 \mathrm{~m}^{3}$ of LNAPL was recovered, which accounted for $44 \%$ of all LNAPL recovered between 2005 and 2015. In March 2007, the LNAPL recovery rates both decreased and increased in October 2007, then the recovery rate stayed high until March 2008. During this period, the recovered LNAPL totaled $43.92 \mathrm{~m}^{3}$. After February 2008, oil recoveries of any substantial volume completely ceased. A substantial rate of LNAPL recovery was newly recorded only on September 2014 and ceased again in March 2015. Between September 2014 and March 2015, $27.12 \mathrm{~m}^{3}$ of LNAPL was recovered.

The cyclical response of the LNAPL recovery strongly coincided with the water table fluctuation, as seen in Figure 9. LNAPL recoveries were only possible after a sufficient decrease in the water table, with most incidences occurring between October and March. Accordingly, LNAPL recovery rates strongly decreased or even ceased when the water table increased. This observation is in accordance with the seasonal cycles of LNAPL entrapment and releases in the pore space caused by water table fluctuations.

\section{Model prediction}

\section{Model parametrization}

Based on the collected samples, we conducted laboratory tests to characterize both oil and aquifer lithologies. Table 1 presents the physical parameters of the main lithologies obtained from retention curve tests, while Table 2 presents the results of LNAPL characterization in the analyzed samples. In our simulations, we used the average values of measured parameters.

\section{LNAPL recovery prediction}

Based on the analytical model presented by Jeong and Chaberneau (2014), we performed simulations em- 
ploying the maximum recorded floating phase recorded in the selected monitoring well to reproduce the theoretical recoverable LNAPL without the effects of seasonal water table fluctuations. A period of fifteen years of pumping was simulated under ideal conditions, assuming that groundwater statistics and recoverable LNAPL within the smear zone could be extracted. To predict the recovery rate based on the water table and floating phase thickness recorded in November 2008, we simulated the recovery of the two most productive pumping wells, PB-06 and PB-07. The parameters employed in the performed simulations are presented in Table 3.

The simulated scenarios of oil recovery in PB-06 and PB-07 are illustrated in Figure 10, while Table 4 summarizes the most important information provided by the simulations.

\section{DISCUSSION}

The high precipitation in tropical and subtropical climates, which is typically above 1,200 mm/year and is concentrated in wet seasons, imposes large variations in the water tables of shallow aquifers (Figures 1 and 2 ). This variation represents the main mechanism that governs the LNAPL distribution in the subsurface and its mobility. The water table fluctuation was previously recognized as a factor that causes the entrapment of LNAPL, as described by the previous works of Kemblowski and Chiang (1990), Marinelli and Durnford (1996), Steffy et al. (1998), Charbeneau et al. (2007), Teramoto and Chang (2017) and Isler et al. (2018). Furthermore, the water table fluctuation also accounts for reductions in effectiveness of LNAPL recoveries via physical extraction (Chaberneau et al., 2000; Kuo et al., 2016).

Most investigation procedures are based on simple and obsolete concepts in which most LNAPL is distributed above the saturated zone, forming a continuous phase in the pore system. Since the 1990s, this concept, known as the "pancake model distribution", has been deemed as obsolete. However, in many regions around the world, the decisions and actions of environmental agencies and consultancies are still guided by the false concept that LNAPL is mostly distributed above the saturated zone as a floating oil phase. For example, in traditional investigations, the soil sampling for hydrocarbon analysis occurs only in the unsaturated and capillary fringe zones. In most environmental investigations, the main indicator of LNAPL is solely based on the presence of floating oil in monitoring wells. Moreover, high concentrations of BTEX (benzene, toluene, ethylbenzene and xylenes) in an aqueous phase are misinterpreted as being transported in the dissolved plume phase and are not seen as a result of a dissolution of entrapped LNAPL. A simple reduction of the floating phase thickness during a water table rise is equivocally associated with the effectiveness of the operating remediation system, despite the low overall recoverability of LNAPL volumes. These incorrect diagnostics and elaborated conceptual models cause existing remediation systems to be ineffective, expensive and environmentally unsustainable.

Regular monitoring provides essential elements to investigate the cycles of entrapment and releases of LNAPL and their impact on the effectiveness of remediation systems based on the pump-and-treat methodology. Empirical observations in the studied site indicate that recovering substantial amounts of LNAPL is possible only when the floating phase thickness is above $30 \mathrm{~cm}$ in monitoring wells. Thus, the floating phase thickness represents an important metric to determine the favorable periods for LNAPL extraction.

The collective understanding of LNAPL behavior in a subsurface was demonstrably improved in the last decade through the emergence of the high-resolution technique Laser Induced Fluorescence (LIF). The emergence of high-resolution techniques, and mainly laser induced fluorescence such as UVOST ${ }^{\circledR}$ (St. Germain and Martin, 2008), has enhanced the current understanding of hydrocarbon behaviors and distributions in a subsurface. Several works based on LIF investigations have demonstrated that the current conceptual and mathematical models cannot reproduce the oil distribution in a saturated zone (Suthersan et al., 2015b; Isler et al., 2018; Gastsios et al., 2018). Investigations with LIF carried out in September 2015 and presented by Isler et al. (2018) show clearly that LNAPL are overwhelmingly distributed in the entrapped phase below the water table. The entrapment condition explains the absence of the floating phase in our monitoring wells in 2015,2016 and 2017.

One of most prominent features of shallow aquifers situated in tropical climates is the wide range in water 
table fluctuations, which is directly related to precipitation amounts. In southeastern Brazil, the high rainy season encompasses the period between October and February. Another factor that likely contributes to water table increases is air entrapments, as described by Gonçalves et al. (2019). In a similar behavior as LNAPL, the air filling the pore system is displaced and becomes distributed as isolated bubbles or ganglia in the center of the pores. Due to air clogging the pores, there is a reduction in the specific yield of the formation, leading to a water table increase. The wide range of water table fluctuations promotes the entrapment of LNAPL below the water table (Marinelli and Durnford, 1996; Steffy et al., 1998; Suthersan et al., 2015b; Teramoto and Chang, 2017), thereby hindering the identification of the extent of the source zone and impeding LNAPL recovery.

The transmissivity of LNAPL, estimated by bail-down tests used to determine the hydraulic conductivity of an aquifer, represents the criteria for conducting oil recoveries (Huntey, 2000; Beckett and Huntley 2015; Palmier et al., 2016; Ahmed et al., 2019). However, the LNAPL transmissivity broadly varies over time in response to water table fluctuations and is not a representative metric for measuring recoverable LNAPL (Gatsios et al., 2018). Determinations of oil transmissivity during prolongated dry seasons, when the water table decreases sufficiently and releases LNAPL from the pores, induces an incorrect remediation design and incorrect oil recovery estimations. Thus, we recommend the abolition of bail-down tests to estimate oil recovery in cases where the water table strongly fluctuates.

The continuous lowering of the water table in our study started in April 2006 and allowed the removal large volumes of LNAPL in October of the same year; $84.57 \mathrm{~m}^{3}$ of LNAPL was recovered in four months and accounted for about $50 \%$ of the total jet fuel recovered during the previous 40 months of pumping. The sudden increase in oil recovery rates from the second half of October 2006 suggests the entry of air into the porous medium that was previously filled by LNAPL and water. The large volume of recovered jet fuel caused a rapid decrease in the thicknesses of the monitoring wells. The most extreme case was observed in a monitoring well located at approximately $160 \mathrm{~m}$ east and upstream of PB-06, where a decrease of $65 \mathrm{~cm}$ in oil thickness in 72 days was recorded. The decrease in oil recovery observed in January 2006 is attributed to the influx of groundwater recharge, thereby leading to an associated water table increase.

In our monitoring, we had a rare opportunity to observe the effect of severe drought on the LNAPL remediation. Coelho et al. (2016) provided a detailed description of the severe drought observed in 2014-2015 in southeast Brazil. Because of the exceptionally reduced precipitation in this period, the groundwater recharge was also anomalously low ( $50 \%$ below the historical average record); this consequently led to strong and anomalous decrease in the water table, as observed in Figure 1 and 2. During the water table reduction, LNAPL was completely released from the porous media, allowing for a high rate of oil recovery by the remediation systems. Due to the strong decrease in the water table recorded in November 2014, the LNAPL migrated downward, increasing the entrapment likelihood, as observed by the LIF tests carried out by Isler et al. (2018) at the study site. Because of the strong entrapment, the opportunity for LNAPL recovery was less frequent.

Assuming a hypothetical and idealized condition where the water table is statistically controlled, a fifteen year simulation of the pumping wells of PB-06 and PB-07 (Figure 9) allowed estimated recoverable volumes of 192.568 and $218.560 \mathrm{~m}^{3}$ of LNAPL, respectively; this result represented the range of theoretical LNAPL that could be recovered. However, due to the seasonal cycles of water table fluctuation, LNAPL recoveries can occur only during four months of dry years. The required time to reach this recovery volume likely would have a timescale of decades or even hundreds of years.

The widely held concept that a remediation system should operate uninterruptedly during the presence of a free phase is not valid in this case. Due to unfeasibility of LNAPL recovery in most period, remediation systems should only operate when the water table decreases sufficiently. Accordingly, remediation systems should operate only in the months of water table retreat (October to January in our study area), since the recovery of LNAPL is not directly related to the pumping rates but is instead related to the available LNAPL after the drainage of water from the pores. At this time, the remediation operation should be extended beyond the pumping wells. 
Teramoto et al. (2019) demonstrated that LIF allow a quantitative assessment of entrapped LNAPL volume via fluorescence intensity. Based on estimations of entrapped oil, it is possible to quantify the recoverable LNAPL volume when the water table falls and releases the non-wetting phase from the pore space.

A serious disadvantage of the pump-and-treat methodology is the large volume of contaminated groundwater that should be extracted and treated over a long period of time, thereby increasing the operation costs. Moreover, there are no benefits to expending resources to extract the contaminant in the aqueous phase; this was demonstrated when the biodegradation rate imposed a narrow limit of plume migration as demonstrated by Teramoto and Chang (2019) in the study site. Thus, the simple maintenance of a remediation system that mostly operates while extracting only water does not represent a sustainable option and should be critically reviewed.

We conclude that remediation should be employed as complementary method to accelerate the restoration of contaminated sites in tropical climates. Under this assumption, a useful strategy for remediation optimization is to establish a tridimensional distribution of LNAPL based on LIF. Continuous monitoring of the water table depth may be used as criteria to define favorable periods in which LNAPL recovery is feasible. The operation of a pump-and-treat system should be employed only in episodic cases in which the water table is low and most LNAPL has been released. The physical extraction of hydrocarbons should be understood as a complementary action to accelerate site restoration based on source removal.

Aggressive remediation alternatives, which mainly comprise thermal methodologies, can destroy organic contaminant mass in the subsurface (Beyke and Fleming, 2005; McGuire et al., 2006; Falciglia et al., 2011; Zhao et al., 2014; Hagele and Mumford, 2014). In most cases, however, the costs of thermal remediation are infeasible and unnecessary due to the absence of human health risks. On the other hand, the Natural Source Zone Depletion method has developed \soutas into an attractive approach in recent years for LNAPL contaminations, as described by Johnson et al. (2006), Kulkarni et al. (2015), McCoy et al. (2015), Eichert et al. (2017), Garg et al. (2017), Tomlinson et al. (2017), Lari et al. (2019), and several others. NSZD encompasses a set of natural processes, including dissolution, volatilization, and biodegradation that causes mass losses of light non-aqueous phase liquid (LNAPL) petroleum hydrocarbon constituents from the subsurface. NSZD is becoming a critical component of hydrocarbon-contaminated site management because the source depletion rates, driven by natural processes, are higher than previously predicted. Furthermore, the amount of mass removed by NSZD processes occurring at most petroleum-contaminated sites is in several cases greater than the LNAPL mass extracted by active remediation. Based on the findings described in this study and those previously presented by Teramoto and Chang (2017) and Teramoto and Chang (2019), NSZD represents the appropriate remediation approach for the study site.

\section{CONCLUSIONS}

This study describes a phenomenological process that associates the entrapment and release of LNAPL in a pore space with seasonal water table fluctuations, with implications for the effectiveness of active remediation systems. Our field data indicates that the performance of physical extraction techniques, such as pump-andtreat remediation, is strongly affected by water table fluctuations, which are intensified in tropical climates. The wide range of water table fluctuations, which commonly is higher than 4 meters in tropical climates, provides favorable conditions for LNAPL entrapment. In the study site, the employed active remediation system was effective for four months during the dry years, when the water table was extensively drained from the pores and the LNAPL gained mobility. The phenomenon presented does not represent a site-specific case; instead, it represents the norm in the tropical climates. The findings presented in this study may therefore have important impacts on contaminated site management schemes.

\section{DATA AVAILABILITY}

The data that support the findings of this study are available from the corresponding author upon reasonable request.

\section{REFERENCES}


Ahmed, W., Palmier, C., Atteia, O., Class, H. 2019. Multiphase Simulation Model for Validating the Estimate of Light Non-Aqueous Phase Liquids (LNAPL) Transmissivity Using Bail-Down Test. Arabian Journal for Science and Engineering , 44 (6), 6099-6107.

American Society for Testing and Materials. 2002. Standard Test Method for Density and Relative Density of Liquids by Digital Density Meter -ASTM D 4052. West Conshohocken, PA.

American Society for Testing and Materials. 2004. Standard Test Method for Interfacial Tension of Oil Against Water by the Ring Method -ASTM D 971 . West Conshohocken, PA.

American Society for Testing and Materials. 2008. Standard Test Method for Kinematic Viscosity of Transparent and Opaque Liquids (and Calculation of Dynamic Viscosity)- ASTM D 445 . West Conshohocken.

Aral, M. M., Liao, B. 2002. Effect of groundwater table fluctuations on LNAPL thickness in monitoring wells. Environmental Geology , 42 (2-3), 151-161.

Baciocchi, R., Berardi, S., Verginelli, I. 2010. Human health risk assessment: Models for predicting the effective exposure duration of on-site receptors exposed to contaminated groundwater. Journal of hazardous materials , 181 (1-3), 226-233.

Bai, G., Brusseau, M. L., \& Miller, R. M. 1997. Biosurfactant-enhanced removal of residual hydrocarbon from soil. Journal of Contaminant Hydrology , 25 (1-2), 157-170.

Beckett, G. D., Huntley, D. 2015. Lnapl transmissivity: a twisted parameter. Groundwater Monitoring $\mathcal{E}^{3}$ Remediation , 35 (3), 20-24. Doi: https://doi.org/10.1111/gwmr.12116

Beyke, G., Fleming, D. 2005. In situ thermal remediation of DNAPL and LNAPL using electrical resistance heating. Remediation Journal: The Journal of Environmental Cleanup Costs, Technologies 85 Techniques , 15 $(3), 5-22$.

Borden, R. C., and Kao, C. M., 1992. Evaluation of groundwater extraction for remediation of petroleumcontaminated aquifers. Water Environment Research, 64(1), 28-36. doi: dx.doi.org/10.2175/WER.64.1.5

Bordignon. R.; Teramoto, E.H.; Chang, K.H. 2015. Caracterização isotópica de $\mathrm{CO}_{2}$ dissolvido em águas subterrâneas em área contaminada por querosene de aviação, município de Paulínia, SP. Águas Subterrâneas. 29(3): 301-314. doi: dx.doi.org/10.14295/ras.v29i3.27979

Charbeneau, R. J., \& Chiang, C. Y. 1995. Estimation of free-hydrocarbon recovery from dual-pump systems. Groundwater, 33 (4), 627-634.

Charbeneau, R. J., Johns, R. T., Lake, L. W., McAdams, M. J. 2000. Free-Product Recovery of Petroleum Hydrocarbon Liquids. Groundwater Monitoring $\& 3$ Remediation, 20 (3), 147-158.

Chatzis, I., Dullien, F. A. L., 1983. Dynamic immiscible displacement mechanisms in pore doublets: heory versus experiment. Journal Colloid Interface Science, 91 (1), 199-222. doi:10.1016/0021-9797(83)90326-0

Chesnaux, R. (2008). Analytical closed-form solutions for assessing pumping cycles, times, and costs required for NAPL remediation. Environmental Geology , 55 (7), 1381-1388. Doi: https://doi.org/10.1007/s00254007-1088-9

Coelho, C. A., Cardoso, D. H., \& Firpo, M. A. 2016. Precipitation diagnostics of an exceptionally dry event in Sao Paulo, Brazil. Theoretical and Applied Climatology, 125 (3-4), 769-784.

Dekker, T. J., \& Abriola, L. M. 2000. The influence of field-scale heterogeneity on the surfactant-enhanced remediation of entrapped nonaqueous phase liquids. Journal of Contaminant Hydrology , 42 (2-4), 219-251.

Dudley, B. 2018. BP statistical review of world energy. BP Statistical Review, London, UK, accessed Aug , 6,2018 . 
Eichert, J., McAlexander, B., Lyverse, M., Michalski, P., \& Sihota, N. 2017. Spatial and temporal variation in natural source zone depletion rates at a former oil refinery. Vadose Zone Journal, 16 (10).

Falciglia, P. P., Giustra, M. G., \& Vagliasindi, F. G. A. 2011. Low-temperature thermal desorption of diesel polluted soil: influence of temperature and soil texture on contaminant removal kinetics. Journal of hazardous materials , 185 (1), 392-400.

Farr, A. M., Houghtalen, R. J., and McWhorter, D. B., 1990. Volume estimation of light nonaqueous phase liquids in porous media.Groundwater , 28(1), 48-56. doi: 10.1111/j.1745-6584.1990.tb02228.x

Garg, S., Newell, C. J., Kulkarni, P. R., King, D. C., Adamson, D. T., Renno, M. I., \& Sale, T. 2017. Overview of natural source zone depletion: processes, controlling factors, and composition change. Groundwater Monitoring 83 Remediation, 37 (3), 62-81.

Gatsios, E., Garcia-Rincon, J., Rayner, J. L., McLaughlan, R. G., \& Davis, G. B. 2018. LNAPL transmissivity as a remediation metric in complex sites under water table fluctuations. Journal of Environmental Management, 215 , 40-48.

Ghosh, J., \& Tick, G. R. 2013. A pore scale investigation of crude oil distribution and removal from homogeneous porous media during surfactant-induced remediation. Journal of Contaminant Hydrology , 155 , 20-30.

Hegele, P. R., \& Mumford, K. G. 2014. Gas production and transport during bench-scale electrical resistance heating of water and trichloroethene. Journal of Contaminant Hydrology , 165 , 24-36.

Harwell, J. H., Sabatini, D. A., \& Knox, R. C. 1999. Surfactants for ground water remediation. Colloids and Surfaces A: Physicochemical and Engineering Aspects , 151 (1-2), 255-268.

Hernandez-Espriu, A., Martinez-Santos, P., Sanchez-Leon, E., \& Marin, L. E. 2012. Free-product plume distribution and recovery modeling prediction in a diesel-contaminated volcanic aquifer. Physics and Chemistry of the Earth, Parts $A / B / C, 37,43-51$.

Huntley, D., Hawk, R. N., and Corley, H. P., 1994. Nonaqueous Phase Hydrocarbon in a Fine-Grained Sandstone: 1. Comparison Between Measured and Predicted Saturations and Mobility. Groundwater , 32(4), 626-634. doi: 10.1111/j.1745-6584.1994.tb00898.x

Huntley, D. 2000. Analytic determination of hydrocarbon transmissivity from baildown tests. Groundwater , $38(1), 46-52$.

Huntley, D., Beckett, G. D. 2002. Persistence of LNAPL sources: relationship between risk reduction and LNAPL recovery. Journal of Contaminant Hydrology , 59 (1-2), 3-26. Doi: https://doi.org/10.1016/S01697722(02)00073-6

ITRC. 2009. Evaluating Natural Source Zone Depletion at Sites with LNAPL. LNAPL-1 . Washington, DC: Interstate Technology and Regulatory Council.

Jawitz, J. W., Annable, M. D., Rao, P. S. C., \& Rhue, R. D. 1998. Field implementation of a Winsor type I surfactant/alcohol mixture for in situ solubilization of a complex LNAPL as a single-phase microemulsion. Environmental Science 83 Technology, 32 (4), 523-530.

Jawitz, J. W., Dai, D., Rao, P. S. C., Annable, M. D., \& Rhue, R. D. 2003. Rate-limited solubilization of multicomponent nonaqueous-phase liquids by flushing with cosolvents and surfactants: modeling data from laboratory and field experiments. Environmental science \&3 technology , 37 (9), 1983-1991.

Jeong, J., and Charbeneau, R. J., 2014. An analytical model for predicting LNAPL distribution and recovery from multi-layered soils. Journal of Contaminant Hydrology , 156, 52-61. doi: 10.1016/j.jconhyd.2013.09.008

Johnson, P. C., Kemblowski, M. W., Colthart, J. D. 1990. Quantitative analysis for the cleanup of hydrocarbon-contaminated soils by in-situ soil venting. Groundwater , 28 (3), 413-429. 
Johnson, P., Lundegard, P., \& Liu, Z. 2006. Source zone natural attenuation at petroleum hydrocarbon spill sites-I: Site-specific assessment approach. Groundwater Monitoring \& Remediation , 26 (4), 82-92.

Johnston, C. D., \& Adamski, M. 2005, August. Relationship between initial and residual LNAPL saturation for different soil types. In Proceedings of the 2005 Petroleum Hydrocarbons and Organic Chemicals in Groundwater $^{(r)}$ : Prevention, Assessment, and Remediation Conference (pp. 29-42). Assessment approach. Groundwater Monitoring \& Remediation, 26 (4), 82-92.

Kaluarachchi, J. J. 1996. Effect of subsurface heterogeneity on free-product recovery from unconfined aquifers. Journal of contaminant hydrology , 22 (1-2), 19-37.

Kemblowski, M. W., and Chiang, C. Y., 1990. Hydrocarbon thickness fluctuations in monitoring wells. Groundwater , 28(2), 244-252. doi: 10.1111/j.1745-6584.1990.tb02252.x

Khalladi, R., Benhabiles, O., Bentahar, F., \& Moulai-Mostefa, N. 2009. Surfactant remediation of diesel fuel polluted soil. Journal of Hazardous Materials , 164 (2-3), 1179-1184.

Kuo, T., Chen, Y., Lin, C., \& Chen, J. 2016. Oil recovery from a fluctuating water table. Petroleum Science and Technology , 34 (17-18), 1562-1567.

Kulkarni, P. R., McHugh, T. E., Newell, C. J., \& Garg, S. 2015. Evaluation of Source-Zone Attenuation at LUFT Sites with Mobile LNAPL. Soil and Sediment Contamination: An International Journal , 24 (8), 917-929.

Lari, K. S., Rayner, J. L., \& Davis, G. B. 2018. Towards characterizing LNAPL remediation endpoints. Journal of Environmental Management, 224, 97-105.

Lari, K. S., Davis, G. B., Rayner, J. L., Bastow, T. P., \& Puzon, G. J. 2019. Natural source zone depletion of LNAPL: A critical review supporting modelling approaches. Water research .

Lee, D. H., Cody, R. D., \& Hoyle, E. L. 2001. Laboratory evaluation of the use of surfactants for ground water remediation and the potential for recycling them. Groundwater Monitoring 85 Remediation, 21 (1), $49-57$.

Lenhard, R. J., and Parker, J. C., 1990. Estimation of free hydrocarbon volume from fluid levels in monitoring wells. Ground Water, 28(1), 57-67. doi: 10.1111/j.1745-6584.1990.tb02229.x

Lenhard, R. J., Sookhak Lari, K., Rayner, J. L., \& Davis, G. B. 2018. Evaluating an analytical model to predict subsurface LNAPL distributions and transmissivity from current and historic fluid levels in groundwater wells: comparing results to numerical simulations. Groundwater Monitoring 83 Remediation , 38 (1), $75-84$.

Li, J. B., Huang, G. H., Chakma, A., \& Zeng, G. M. 2003. Numerical simulation of dual-phase vacuum extraction to remove nonaqueous phase liquids in subsurface. Practice Periodical of Hazardous, Toxic, and Radioactive Waste Management, 7 (2), 106-113.

MacDonald, J. A., Kavanaugh, M. C. 1994. Restoring contaminated groundwater: an achievable goal?. Environmental Science 83 Technology, 28 (8), 362A-368A. Doi: https://doi.org/10.1021/es00057a001

McCoy, K., Zimbron, J., Sale, T., \& Lyverse, M. 2015. Measurement of natural losses of LNAPL using CO2 traps. Groundwater, 53 (4), 658-667.

McCray, J. E., Tick, G. R., Jawitz, J. W., Gierke, J. S., Brusseau, M. L., Falta, R. W., ... \& Wood, A. L. 2011. Remediation of NAPL source zones: Lessons learned from field studies at Hill and Dover AFB. Groundwater , 49 (5), 727-744.

McGuire, T. M., McDade, J. M., \& Newell, C. J. 2006. Performance of DNAPL source depletion technologies at 59 chlorinated solvent-impacted sites. Groundwater Monitoring 63 Remediation , 26 (1), 73-84. 
Mercer, J. W. 1990. Basics of pump-and-treat ground-water remediation technology . Robert S. Kerr Environmental Research Laboratory, Office of Research and Development, US Environmental Protection Agency.

Newell, C. J., \& Adamson, D. T. 2005. Planning-level source decay models to evaluate impact of source depletion on remediation time frame. Remediation Journal: The Journal of Environmental Cleanup Costs, Technologies \& Techniques, 15 (4), 27-47.

Ossai, I. C., Ahmed, A., Hassan, A., \& Hamid, F. S. 2019. Remediation of soil and water contaminated with petroleum hydrocarbon: A review. Environmental Technology \& Innovation . Doi: https://doi.org/10.1016/j.eti.2019.100526

Palmier, C., Dodt, M., Atteia, O. 2016. Comparison of Oil Transmissivity Methods Using Bail-Down Test Data. Groundwater Monitoring \& Remediation, 36 (3), 73-83.

Peters, C. A., Knightes, C. D., \& Brown, D. G. 1999. Long-term composition dynamics of PAH-containing NAPLs and implications for risk assessment. Environmental Science $\mathcal{E}$ Technology , 33 (24), 4499-4507.

Ramsburg, C. A., Pennell, K. D., Abriola, L. M., Daniels, G., Drummond, C. D., Gamache, M., ... \& Yavaraski, T. P. (2005). Pilot-scale demonstration of surfactant-enhanced PCE solubilization at the Bachman Road site. 2. System operation and evaluation. Environmental science 8 technology, 39 (6), 1791-1801.

Saenton, S., Illangasekare, T. H., Soga, K., \& Saba, T. A. 2002. Effects of source zone heterogeneity on surfactant-enhanced NAPL dissolution and resulting remediation end-points. Journal of Contaminant Hydrology , 59 (1-2), 27-44.

Saenton, S., \& Illangasekare, T. H. (2013). Effects of incomplete remediation of NAPL-contaminated aquifers: experimental and numerical modeling investigations. Applied Water Science, 3 (2), 401-414.

Sleep, B. E., Sehayek, L., \& Chien, C. C. 2000. A modeling and experimental study of light nonaqueous phase liquid (LNAPL) accumulation in wells and LNAPL recovery from wells. Water Resources Research , 36 (12), 3535-3545.

Steffy, D. A., Johnston, C. D., \& Barry, D. A. 1998. Numerical simulations and long-column tests of LNAPL displacement and trapping by a fluctuating water table. Journal of Soil contamination, 7 (3), 325-356.

St. Germain, R., and T. Martin, 2008. North American Environmental Field Conference \& Exposition - LIF Workshop Slides, Tampa, FL. https://clu-in.org/download/char/lif/Dakota-Technologies-LIF-Workshop.pdf

Steffy, D. A., Johnston, C., \& Barry, D. A. 1995. A field study of the vertical immiscible displacement of LNAPL associated with a fluctuating water table. In Groundwater Quality: Remediation and Protection (No. ECOL-CONF-1995-001). International Association of Hydrological Sciences.

Steffy, D. A., Johnston, C. D., \& Barry. D. A. 1998. Numerical simulations and long-column tests of LNAPL displacement and trapping by a fluctuating water table. Journal of Soil contamination . 7 (3). 325-356.

Suthersan, S., Killenbeck, E., Potter, S., Divine, C., \& LeFrancois, M. 2015a. Resurgence of pump and treat solutions: Directed groundwater recirculation. Groundwater Monitoring 83 Remediation , 35 (2), 23-29.

Suthersan, S., Koons, B., \& Schnobrich, M. 2015b. Contemporary management of sites with petroleum LNAPL presence. Groundwater Monitoring $\&$ Remediation, 35 (1), 23-29. Doi: doi.org/10.1111/gwmr.12099

Teramoto, E. H., \& Chang, H. K. 2017. Field data and numerical simulation of btex concentration trends under water table fluctuations: Example of a jet fuel-contaminated site in Brazil. Journal of Contaminant Hydrology , 198 , 37-47.

Teramoto, E. H., \& Chang, H. K. (2018). Metodos WTF e simulacao numerica de fluxo para estimativa de recarga-exemplo Aquifero Rio Claro em Paulinia/SP. Aguas Subterraneas , 32 (2), 173-180.

Thornton, S. F., Tobin, K., \& Smith, J. W. (2013). Comparison of constant and transient-source zones on simulated contaminant plume evolution in groundwater: Implications for hydrogeological risk assessment. Groundwater Monitoring $\&$ Remediation, 33 (3), 78-91. 
Tomlinson, D. W., Rivett, M. O., Wealthall, G. P., \& Sweeney, R. E. (2017). Understanding complex LNAPL sites: Illustrated handbook of LNAPL transport and fate in the subsurface. Journal of Environmental Management, 204, 748-756.

Waddill, D. W., \& Parker, J. C. 1997. Simulated recovery of light, nonaqueous phase liquid from unconfined heterogeneous aquifers. Groundwater, 35 (6), 938-947.

Wang, W., Kuo, T., Chen, Y., Fan, K., Liang, H., \& Chen, J. 2014. Effect of precipitation on LNAPL recovery performance: An integration of laboratory and field results. Journal of Petroleum Science and Engineering, $116,1-7$.

West, C. C., \& Harwell, J. H. 1992. Surfactants and subsurface remediation. Environmental Science \& Technology , 26 (12), 2324-2330.

Zhao, C., Mumford, K. G., \& Kueper, B. H. (2014). Laboratory study of non-aqueous phase liquid and water co-boiling during thermal treatment. Journal of Contaminant Hydrology , 164 , 49-58.

\section{Hosted file}

Table.docx available at https://authorea.com/users/306545/articles/437515-seasonal-effectivenessof-pump-and-treat-remediation-impacted-by-water-table-fluctuation

\section{Hosted file}

Figure.docx available at https: //authorea.com/users/306545/articles/437515-seasonal-effectivenessof-pump-and-treat-remediation-impacted-by-water-table-fluctuation 